\title{
The relationship between self-rated health and objective health status: a population-based study
}

\author{
Shunquan $\mathrm{Wu}^{\dagger}$, Rui Wang ${ }^{\dagger}$, Yanfang Zhao, Xiuqiang Ma, Meijing Wu, Xiaoyan Yan and Jia He
}

\begin{abstract}
Background: Self-rated health $(\mathrm{SRH})$, a subjective assessment of health status, is extensively used in the public health field. However, whether SRH can reflect the objective health status is still debatable. We aim to reveal the relationship between $\mathrm{SRH}$ and objective health status in the general population.

Methods: We assessed the relationship between SRH and objective health status by examining the prevalence of diseases, laboratory parameters, and some health-related factors in different SRH groups. Data were collected from 18,000 residents randomly sampled from the general population in five cities of China (3,600 in each city). SRH was assessed by a single-item health measure with five options: "very good," "good," "fair," "bad," and "very bad." The differences in prevalence of diseases, laboratory parameters, and health-related factors between the "healthy" (very good plus good), "relatively healthy" (fair), and "unhealthy" (bad plus very bad) groups were examined. The odds ratios (ORs) referenced by the healthy group were calculated using logistic regression analysis.
\end{abstract}

Results: The prevalence of all diseases was associated with poorer SRH. The tendency was more prominent in cardio-cerebral vascular diseases, visual impairment, and mental illnesses with larger ORs. Residents with abnormalities in laboratory parameters tended to have poorer SRH, with ORs ranging from 1.62 (for triglyceride) to 3.48 (for hemoglobin among men) in a comparison of the unhealthy and healthy groups. Most of the healthrelated factors regarded as risks were associated with poorer SRH. Among them, life and work pressure, poor spiritual status, and poor quality of interpersonal relationships were the most significant factors.

Conclusions: SRH is consistent with objective health status and can serve as a global measure of health status in the general population.

Keywords: Self-rated health, Health status, Disease prevalence, Laboratory parameters, Health-related factors

\section{Background}

Self-rated health (SRH) (also known as self-assessed health or self-perceived health) refers to a single-item health measure in which individuals rate the current status of their own health on a four- or five-point scale from excellent to poor. It is popular for its simplicity and has been extensively studied in Western populations. A series of national and international analyses has consistently shown that SRH is a good predictor of mortality of various diseases [1-3]. Furthermore, many researchers have attempted to investigate the factors related to SRH and have found that SRH is strongly associated with

\footnotetext{
*Correspondence: hejia63@yahoo.com

${ }^{\dagger}$ Equal contributors

Department of Health Statistics, Second Military Medical University, No.800 of XiangYin Road, Shanghai 200433, China
}

morbidity and disability [4-6]. Economic or social factors are also its main determinants [7-9].

SRH is a subjective reflection of health status, called "perceived" or "subjective" health. It has been widely studied in survey research $[3,7,8]$. However, most of the studies concerning SRH have focused on specific age groups, sex groups, or patient groups [10-12]. Studies reporting SRH among the general population are few. Relative to SRH, some indicators provide direct evidence to the health status of individuals, including previous and current diseases (diagnosed by physicians), and clinical parameters measured in the hospital; these have been termed as "actual" or "objective" health. Some health-related factors, such as demographic characteristics, health history, life habit, life stress and work strain, are closely associated with objective health. 
There is a complex relationship between subjective and objective health [13]. Some studies reported that old people perceived their health in positive terms and tended to over-estimate their health [14-16], while other studies found that old people tended to report poorer health than others who were with similar objective health conditions $[15,17,18]$. Is subjective health consistent with objective health? Can SRH serve as a global measure of health status in the general population? The answers are still debatable. Thus, the assessment of the relationship between SRH and objective health status is important, for this determines whether SRH can serve as an indicator of objective health status.

\section{Methods}

This study examined the association between SRH and objective health status through a comprehensive collection of data on disease prevalence, laboratory parameters, and health-related factors in a randomly selected sample from five cities of China: Shanghai, Beijing, Xi'an, Wuhan and Guangzhou. We attempted to determine the relationship between $\mathrm{SRH}$ and objective health status in this population sample and to identify the factors that best discriminate the different SRH groups.

\section{Study design and sample}

We used a part of the data from our previous epidemiological survey on gastrointestinal diseases in five cities of China. The details of the methodology of the survey have been published elsewhere [19], and are briefly described here. The survey was administered to 18,000 residents aged 18-80 years (3,600 in each city) from April 2007 to January 2008. Eligibility criteria were based on age and the mental and physical ability of subjects to participate in the survey. Residents who were illiterate, not in the 18-80 age group, or suffering from psychiatric illnesses or other disabilities were excluded from the study. They were sampled using a randomized, stratified, multiple-stage sampling method, with the age/gender distribution of the sample in accord with the distribution of local population according to the population census statistics published by the government. Thus, the sample would not be affected by the original impetus of the survey. In the first stage, one or more districts from the urban stratum and one or more counties from the rural stratum were randomly selected from each region. In the second stage, one or more blocks from the urban districts and one or more townships from the rural counties were randomly selected. In the third stage, one or more residential areas from the urban blocks and one or more villages from the rural townships were randomly sampled. Questionnaires were self-completed, with trained interviewers giving explanation on any unclear questions. The entire procedure was overseen by the supervisors to ensure the quality of the survey.

\section{Measurements}

Demographic information were gathered on gender, age, weight, height, marital status (married, unmarried, divorced, or widowed), educational level (less than primary school, completed only primary school, completed secondary school, completed high school, completed college/ pre-university/university, master's degree, or doctoral degree), total family monthly income $(<\mathrm{RMB} 2,000, \mathrm{RMB}$ 2,000-4,999, RMB 5,000-9,999, or $\geq \operatorname{RMB} 10,000$ ), etc. We used a single-item measure of subjective health-"In general, how would you rate your current health status?"-to assess self-ratings of health. Five options, which were recommended by the World Health Organization (WHO) [20] and the European Network for the Calculation of Health Expectancies (Euro-PEVES) 2 group [21], were listed: "very good," "good," "fair," "bad," or "very bad."

To assess the relationship between SRH and objective health status, subjects were asked to report whether they had been diagnosed with chronic diseases, including hypertension, cerebrovascular disorder, diabetes mellitus, and chronic bronchitis. Blood sampling was carried out after overnight fasting at the Second Military Medical University Changhai Hospital in Shanghai, but this was not done in the other four cities. The following parameters were measured to assess the subjects' health status: red blood cell (RBC), hemoglobin (HGB), aspartate aminotransferase (AST), total cholesterol (TC), triglyceride (TG), low-density lipoprotein cholesterol (LDL-C), and fasting plasma glucose (FPG). RBC and HGB indicate the body's ability to transport oxygen to tissues. AST and TC are indicators that mainly reflect hepatic dysfunction. High levels of TG and LDL-C are two major risk factors for cardiovascular and cerebral diseases. Plasma glucose provides the energy cells require and must be maintained at a certain level in order to sustain the body's needs. Body mass index (BMI) was calculated as weight in kilograms divided by the square of height in meters, and the WHO criterion for Asian populations was used to classify subjects as obese, overweight, normal weight, and underweight [22]. Data on some healthrelated factors were also collected, including body weight five years ago, tobacco use, frequency of physical activity, life stress, work strain, spiritual status, and quality of interpersonal relationships. Tobacco use was measured with a single question: "Do you currently smoke?" Six options were given: "no," "1-5 cigarettes/day," "6-10 cigarettes/day," "11-15 cigarettes/day," "16-20 cigarettes/day," or " $\geq 21$ cigarettes/day." Frequency of physical activity was measured with the following question: "How often do you engage in physical activities (e.g., physically active work, walking, riding a bike, and doing 
exercises)?" Four options were given: "never," "<4 times per month," "at least once a week," or "at least once a day." Life stress was measured by asking "Overall, do you feel stress in your daily life?" and work strain was measured by asking "Overall, do you feel stress in your daily work?" Life stress and work strain were assessed on a five-point scale: "no," "a little," "moderate," "quite a lot," and "extreme." Spiritual status was measured by asking "Overall, how would you rate your spirituality?" and quality of interpersonal relationships was measured by asking "Overall, how would you rate your quality of interpersonal relationships?" Spiritual status and quality of interpersonal relationships were assessed by "very good," "good," "moderate," "bad," or "very bad." Women were also asked to answer their ages at menopause.

\section{Statistical analysis}

All the data were doubly input into the database by two independent professional data processors using EpiData 3.1. Statistical Analysis System (SAS) 9.1.3 was used for analyzing the survey data. Data are expressed as mean \pm standard deviation (SD). For statistical comparison, the differences among the "healthy" (very good plus good), "relatively healthy" (fair), and "unhealthy" (bad plus very bad) groups were examined, because it was difficult to determine whether "fair" should be defined as "good health" or "poor health," and because only a few subjects rated their health as very good (1,770 subjects) or very bad (58 subjects). Statistical significance for laboratory parameters among different groups was determined by using an analysis of variance with Bonferroni's multiplecomparison tests. The odds ratios (ORs) and 95\% confidence intervals (CIs) for the "relatively healthy" and "unhealthy" groups were calculated referenced by the "healthy" group, using logistic regression analysis by controlling for gender, age, region, marital status, educational level, current work, family income, current smoking, current drinking, frequency of physical activity, and chronic diseases. All hypothesis tests used two-sided tests and a p-value less than 0.05 was considered statistically significant.

\section{Ethics}

All the subjects had been informed that their records might be used for analysis, and had signed a written informed consent form before participation. The present study was approved by the ethics committee of Second Military Medical University.

\section{Results}

\section{Demographic information}

Among the 18,000 subjects, 16,091 actually answered the questionnaires; however, 13 were excluded from the analysis because of considerable missing data or logistic errors, and another 4 were excluded because they did not answer the general health item. Data from a total of 16,074 subjects were utilized in the statistical analysis, including 8,388 females (52.18\%) and 7,686 males (47.82\%). These subjects had very little missing data (less than 1\%), and we excluded the subjects from relevant analysis if they do have missing data on certain items. Subjects' demographic details are shown in Table 1 . The mean age was 42.6 ( \pm 15.2$)$ years. Among them, 1,770 subjects (11.01\%) rated their health as very good, 7,581 (47.16\%) as good, $5,803(36.10 \%)$ as fair, $862(5.36 \%)$ as bad, and $58(0.36 \%)$ as very bad. Age was negatively correlated with health rating. A total of 3,151 subjects completed the blood sampling in Shanghai with data suitable for analysis, including 1,749 females (55.51\%) and 1,402 males (44.49\%), with mean age of $47.7( \pm 14.1)$ years. A total of 164 subjects (5.20\%) rated their health as very good, 1,347 (42.75\%) as good, 1,492 (47.35\%) as fair, $141(4.47 \%)$ as bad, and 7 $(0.22 \%)$ as very bad. Similarly, the older the subjects were, the poorer they rated their health. The objective health status of the "healthy" (very good plus good), "relatively healthy" (fair), and "unhealthy" (bad plus very bad) groups were compared.

\section{Disease prevalence}

Table 2 presents the prevalence of various diseases by $\mathrm{SRH}$ status, including cardio-cerebral vascular diseases, digestive diseases, respiratory diseases, and mental illnesses. Logistic regression analysis showed that significant increases in the prevalence of all diseases were associated with a lower SRH, adjusting for gender, age, region, marital status, educational level, current work, family income, current smoking, current drinking, frequency of physical activity, and other chronic diseases. The ORs were at least twofold when comparing the unhealthy group with the healthy group, apart from for chronic pharyngitis (OR $1.65[1.29,2.11])$ and osteoarthritis (OR 1.54 [1.13, 2.09]), and there were larger ORs for cardio-cerebral vascular diseases, visual impairment, and mental illnesses. As for tristimania, the OR was 14.14 [5.60, 35.73].

\section{Laboratory parameters}

Laboratory parameters of the three groups by SRH status are presented in Table 3. RBC and HGB were significantly lower in the relatively healthy and unhealthy groups when compared with the healthy group. Levels of AST, TC, TG, LDL-C, and FPG were significantly higher in the relatively healthy and unhealthy groups than in the healthy group.

Abnormalities in laboratory parameters by SRH status adjusted for gender (except for RBC and HGB), age, marital status, educational level, current work, family income, current smoking, current drinking, and frequency 
Table 1 Demographic information of the subjects

\begin{tabular}{lcc}
\hline & $\mathbf{n}$ (female/male) & Mean age (SD) \\
\hline Subjects in all five cities & $16074(8388 / 7686)$ & \\
\hline Total & $1770(845 / 925)$ & $42.6(15.2)$ \\
\hline SRH & $7581(3773 / 3808)$ & $34.7(12.7)$ \\
\hline very good & $5803(3233 / 2570)$ & $40.1(14.3)$ \\
\hline good & $862(506 / 356)$ & $46.0(15.0)$ \\
\hline fair & $58(31 / 27)$ & $55.0(14.6)$ \\
\hline bad & $53.8(16.2)$ \\
\hline very bad & $3151(1749 / 1402)$ & \\
\hline Subjects in Shanghai who have completed the blood sampling & $47.7(14.1)$ \\
\hline Total & $164(74 / 90)$ & \\
\hline SRH & $1347(694 / 653)$ & $41.5(13.6)$ \\
\hline very good & $1492(890 / 602)$ & $44.6(14.0)$ \\
\hline good & $141(88 / 53)$ & $50.3(13.2)$ \\
\hline fair & $7(3 / 4)$ & $58.0(13.0)$ \\
\hline bad & $47.6(16.5)$ \\
\hline very bad &
\end{tabular}

* $p$-values for mean ages.

Table 2 Disease prevalence by self-rated health status

\begin{tabular}{|c|c|c|c|c|c|}
\hline & \multirow{2}{*}{$\begin{array}{l}\text { Healthy } \\
n(\%)\end{array}$} & \multicolumn{2}{|c|}{ Relatively healthy } & \multicolumn{2}{|l|}{ Unhealthy } \\
\hline & & $n(\%)$ & OR $[95 \% \mathrm{Cl}]$ & $n(\%)$ & OR $[95 \% \mathrm{Cl}]$ \\
\hline Hypertension & $615(6.58)$ & $1017(17.53)$ & $1.83[1.62,2.06]$ & $282(30.65)$ & $2.61[2.16,3.15]$ \\
\hline Cerebrovascular disorder & $93(0.99)$ & $222(3.83)$ & $2.00[1.54,2.58]$ & $119(12.93)$ & $4.82[3.53,6.58]$ \\
\hline Angina & $53(0.57)$ & $122(2.10)$ & $1.88[1.34,2.63]$ & $80(8.70)$ & $6.00[4.07,8.86]$ \\
\hline Diabetes mellitus & $85(0.91)$ & $238(4.10)$ & $2.86[2.20,3.72]$ & $90(9.78)$ & $6.36[4.54,8.92]$ \\
\hline Dyspepsia & $351(3.75)$ & $525(9.05)$ & $1.81[1.56,2.10]$ & $137(14.89)$ & $2.76[2.19,3.49]$ \\
\hline Gastritis & $693(7.41)$ & $966(16.65)$ & $1.74[1.56,1.95]$ & $213(23.15)$ & $2.37[1.96,2.87]$ \\
\hline Peptic ulcer & $213(2.28)$ & $323(5.57)$ & $1.63[1.35,1.97]$ & $86(9.35)$ & $2.50[1.88,3.33]$ \\
\hline $\mathrm{IBD}$ & $100(1.07)$ & $146(2.52)$ & $1.75[1.33,2.28]$ & $51(5.54)$ & $3.14[2.16,4.58]$ \\
\hline Liver disorder & $196(2.10)$ & $324(5.58)$ & $2.00[1.65,2.43]$ & $80(8.70)$ & $3.58[2.65,4.83]$ \\
\hline Gallbladder disorder & $241(2.58)$ & $353(6.08)$ & $1.43[1.19,1.70]$ & $94(10.22)$ & $2.13[1.62,2.80]$ \\
\hline Renal disorder & $120(1.28)$ & $212(3.65)$ & $2.23[1.76,2.84]$ & $84(9.13)$ & $4.41[3.20,6.07]$ \\
\hline Chronic bronchitis & $183(1.96)$ & $346(5.96)$ & $2.05[1.69,2.48]$ & $100(10.87)$ & $2.34[1.77,3.10]$ \\
\hline Asthma & $45(0.48)$ & $75(1.29)$ & $1.57[1.06,2.32]$ & $35(3.80)$ & $3.57[2.18,5.86]$ \\
\hline Chronic pharyngitis & $518(5.54)$ & $654(11.27)$ & $1.65[1.45,1.88]$ & $100(10.87)$ & $1.65[1.29,2.11]$ \\
\hline Chronic cough & $98(1.05)$ & $188(3.24)$ & $1.90[1.46,2.45]$ & 55 (5.98) & $2.45[1.70,3.53]$ \\
\hline Eczema & $80(0.86)$ & $136(2.34)$ & $1.98[1.48,2.66]$ & $28(3.04)$ & $3.29[2.04,5.30]$ \\
\hline Rheumatoid arthritis & $267(2.86)$ & $352(6.07)$ & $1.44[1.21,1.71]$ & $169(18.37)$ & $2.48[1.96,3.13]$ \\
\hline Osteoarthritis & $176(1.88)$ & $289(4.98)$ & $1.61[1.31,1.97]$ & $73(7.93)$ & $1.54[1.13,2.09]$ \\
\hline Severe visual impairment & $35(0.37)$ & $60(1.03)$ & $1.69[1.09,2.62]$ & $35(3.80)$ & $4.58[2.70,7.78]$ \\
\hline Anxiety neurosis & $15(0.16)$ & $28(0.48)$ & $1.98[1.07,2.90]$ & $14(1.52)$ & $4.48[2.05,9.76]$ \\
\hline Tristimania & $8(0.09)$ & $32(0.55)$ & $4.67[2.15,10.13]$ & $15(1.63)$ & $14.14[5.60,35.73]$ \\
\hline
\end{tabular}

$\mathrm{n}=16074$.

The odds ratios were calculated referenced by the "healthy" group, using logistic regression analysis by controlling for gender, age, region, marital status, educational level, current work, family income, current smoking, current drinking, frequency of physical activity, and other chronic diseases.

IBD: inflammatory bowel disease. 
Table 3 Subjects' laboratory parameters by self-rated health status

\begin{tabular}{llll}
\hline & Healthy & Relatively healthy & Unhealthy \\
\hline RBC $\left(10^{12} / \mathrm{L}\right)$ & $4.76 \pm 0.48$ & $4.68 \pm 0.45^{*}$ & $4.59 \pm 0.45^{*}$ \\
\hline $\mathrm{HGB}(\mathrm{g} / \mathrm{L})$ & $138.8 \pm 16.1$ & $136.7 \pm 15.9^{*}$ & $135.1 \pm 15.5^{*}$ \\
\hline AST $(\mathrm{U} / \mathrm{L})$ & $23.4 \pm 11.1$ & $24.5 \pm 13.2^{*}$ & $26.0 \pm 11.9^{*}$ \\
\hline $\mathrm{TC}(\mathrm{mmol} / \mathrm{L})$ & $4.85 \pm 1.46$ & $5.00 \pm 0.96^{*}$ & $5.21 \pm 1.17^{*}$ \\
\hline $\mathrm{TG}(\mathrm{mmol} / \mathrm{L})$ & $1.40 \pm 1.15$ & $1.52 \pm 1.21^{*}$ & $1.61 \pm 1.18^{*}$ \\
\hline $\mathrm{LDL}-\mathrm{C}(\mathrm{mmol} / \mathrm{L})$ & $3.12 \pm 0.83$ & $3.22 \pm 0.84^{*}$ & $3.24 \pm 0.82^{*}$ \\
\hline $\mathrm{FPG}(\mathrm{mmol} / \mathrm{L})$ & $5.17 \pm 1.21$ & $5.38 \pm 1.55^{*}$ & $5.58 \pm 1.66^{*}$ \\
\hline
\end{tabular}

$\mathrm{n}=3151$.

Data are mean $\pm S D$

Statistical significance was determined using Bonferroni's

multiple-comparison tests.

${ }^{*} \mathrm{p}<0.05$, comparing with the healthy group.

RBC: red blood cell.

HGB: hemoglobin.

AST: aspartate aminotransferase.

TC: total cholesterol.

TG: triglyceride.

LDL-C: low-density lipoprotein cholesterol.

FPG: fasting plasma glucose.

of physical activity are shown in Table 4 . The cut-off values for abnormalities were defined by Changhai Hospital according to the criteria for the Chinese people. For RBC, HGB among women, TC, and FPG, significantly higher ORs were observed in the relatively healthy and unhealthy groups than in the healthy group. For HGB among men, AST, TG, and LDL-C, the ORs were significantly higher in the unhealthy group than in the healthy group.

\section{Health-related factors}

The health-related factors regarded as risks are shown in Table 5. For underweight, marital status, low income, physical activities, life stress, work strain, spiritual status, and quality of interpersonal relationships, significantly higher ORs were observed in the relatively healthy and unhealthy groups than in the healthy group. The ORs for weight loss, low level of education, and early menopause were significantly higher in the unhealthy group than in the healthy group. Among all the factors, life and work pressure, poor spiritual status, and bad quality of interpersonal relationships had larger ORs, which indicates that these factors had a considerable impact on people's health. The ORs for obesity and smoking were not statistically significant. All the ORs were adjusted by gender (except for "age at menopause"), age, region, health-related factors (including marital status, educational level, current work, family income, current smoking, current drinking, frequency of physical activity, but excluding itself), and chronic diseases, using logistic regression analysis.

\section{Discussion}

This study aimed to determine whether SRH could reflect objective health status and serve as a global measure of health status in the general population. For this purpose, we examined the relationships between SRH and the following: (1) prevalence of diseases diagnosed by the physicians, (2) laboratory parameters examined in the hospital, and (3) health-related factors that were regarded as risks. We found that lower SRH was associated with significant increases in the prevalence of all the diseases and abnormalities in laboratory parameters. Some health-related factors, including underweight, weight loss, marital status, education, low income, early menopause, physical activities, life stress, work strain, spiritual status, and quality of interpersonal relationships, were significantly associated with SRH. This suggests that individuals

Table 4 Laboratory parameters abnormalities by self-rated health status

\begin{tabular}{|c|c|c|c|c|c|}
\hline \multirow{2}{*}{$\begin{array}{l}\text { Cut-off values for } \\
\text { abnormalities }\end{array}$} & \multirow{2}{*}{$\begin{array}{l}\text { Healthy } \\
n(\%)\end{array}$} & \multicolumn{2}{|c|}{ Relatively healthy } & \multicolumn{2}{|l|}{ Unhealthy } \\
\hline & & $n(\%)$ & OR $[95 \% \mathrm{Cl}]$ & $n(\%)$ & OR $[95 \% \mathrm{Cl}]$ \\
\hline $\mathrm{RBC}<3.5 \times 10^{12} / \mathrm{L}^{\mathrm{a}}$ & $54(7.03)$ & 79 (8.88) & $1.58[1.09,2.17]$ & $10(10.99)$ & $1.96[1.04,3.89]$ \\
\hline $\mathrm{RBC}<4.0 \times 10^{12} / \mathrm{L}^{\mathrm{b}}$ & $11(1.48)$ & $23(3.82)$ & $2.98[1.54,5.72]$ & $3(5.26)$ & $3.24[1.47,10.24]$ \\
\hline $\mathrm{HGB}<110 \mathrm{~g} / \mathrm{L}^{\mathrm{a}}$ & $35(4.56)$ & $58(6.52)$ & $1.43[1.02,2.05]$ & $8(8.79)$ & $1.92[1.15,4.20]$ \\
\hline $\mathrm{HGB}<120 \mathrm{~g} / \mathrm{L}^{\mathrm{b}}$ & $16(2.15)$ & $18(2.99)$ & $1.38[0.74,2.94]$ & $4(7.02)$ & $3.48[1.23,6.04]$ \\
\hline AST $>=64 \mathrm{U} / \mathrm{L}$ & $14(0.93)$ & $28(1.88)$ & $1.64[0.85,3.12]$ & $4(2.70)$ & $2.70[1.65,4.19]$ \\
\hline $\mathrm{TC}>5.8 \mathrm{mmol} / \mathrm{L}$ & $102(6.75)$ & $158(10.59)$ & $1.30[1.01,1.70]$ & $24(16.22)$ & $1.72[1.05,2.84]$ \\
\hline $\mathrm{TG}>2.0 \mathrm{mmol} / \mathrm{L}$ & $244(16.15)$ & $293(19.64)$ & $1.17[0.96,1.43]$ & $37(25.00)$ & $1.62[1.07,2.47]$ \\
\hline $\mathrm{LDL}-\mathrm{C}>4.9 \mathrm{mmol} / \mathrm{L}$ & $40(2.65)$ & $43(2.88)$ & $0.86[0.55,1.36]$ & $12(8.11)$ & $2.31[1.13,4.69]$ \\
\hline $\mathrm{FPG}>6.2 \mathrm{mmol} / \mathrm{L}$ & $119(7.88)$ & $194(13.00)$ & $1.49[1.15,1.91]$ & $26(17.57)$ & $1.84[1.09,2.93]$ \\
\hline
\end{tabular}

$\mathrm{n}=3151$.

The odds ratios were calculated referenced by the "healthy" group, using logistic regression analysis by controlling for gender (except for RBC and HGB), age,

marital status, educational level, current work, family income, current smoking, current drinking, frequency of physical activity.

a calculated only among women.

${ }^{b}$ calculated only among men.

For abbreviations see Table 3 . 
Table 5 Health-related factors regarded as risks by self-rated health status

\begin{tabular}{|c|c|c|c|c|c|}
\hline & \multirow{2}{*}{$\begin{array}{l}\text { Healthy } \\
n(\%)\end{array}$} & \multicolumn{2}{|c|}{ Relatively healthy } & \multicolumn{2}{|l|}{ Unhealthy } \\
\hline & & $n(\%)$ & OR $[95 \% \mathrm{Cl}]$ & $n(\%)$ & OR $[95 \% \mathrm{Cl}]$ \\
\hline BMl: $<18.5$ kg/m² & $905(9.68)$ & $536(9.24)$ & $1.26[1.11,1.42]$ & $110(11.96)$ & $1.86[1.47,2.36]$ \\
\hline Weight loss: $\geq 5 \mathrm{~kg}$, compared with 5 years ago & $502(5.37)$ & $440(7.58)$ & $1.14[0.99,1.32]$ & $150(16.30)$ & $2.01[1.62,2.50]$ \\
\hline Marital status: divorced/widowed & $249(2.66)$ & $340(5.86)$ & $1.37[1.14,1.65]$ & $122(13.26)$ & $1.69[1.30,2.21]$ \\
\hline The highest level of education: less than primary school & $593(6.34)$ & $612(10.55)$ & $0.98[0.85,1.14]$ & $282(30.65)$ & $1.59[1.29,1.97]$ \\
\hline Total income of family per month: $<2000$ Yuan & $4942(52.85)$ & $3190(54.97)$ & $1.09[1.01,1.18]$ & $681(74.02)$ & $1.59[1.33,1.90]$ \\
\hline Current smoking: $>20$ cigarettes per day & $382(4.09)$ & $248(4.27)$ & $1.02[0.85,1.23]$ & $50(5.43)$ & $1.16[0.83,1.63]$ \\
\hline Age of menopause: ${ }^{a} \leq 45$ years old & $196(4.24)$ & $238(7.36)$ & $1.09[0.88,1.34]$ & $105(19.55)$ & $1.68[1.26,2.25]$ \\
\hline Frequency of physical activity: $<4$ times per month & $1827(19.54)$ & $1421(24.49)$ & $1.56[1.44,1.70]$ & $246(26.74)$ & $2.39[2.02,2.84]$ \\
\hline Life stress: quite a lot/extreme & $686(7.34)$ & $837(14.42)$ & $2.33[2.08,2.62]$ & $292(31.74)$ & $6.98[5.79,8.42]$ \\
\hline Work strain: quite a lot/extreme & $560(5.99)$ & $590(10.17)$ & $2.07[1.81,2.35]$ & $187(20.33)$ & $5.32[4.31,6.57]$ \\
\hline Spiritual status: bad/very bad & $45(0.48)$ & $204(3.52)$ & $6.92[4.96,9.66]$ & $282(30.65)$ & $66.03[46.37,94.02]$ \\
\hline Quality of interpersonal relationships: bad/very bad & $68(0.73)$ & $129(2.22)$ & $2.54[1.86,3.46]$ & $102(11.09)$ & $10.24[7.14,14.69]$ \\
\hline
\end{tabular}

$\mathrm{n}=16074$.

The odds ratios were calculated referenced by the "healthy" group, using logistic regression analysis by controlling for gender (except for "age of menopause"), age, region, health-related factors (including marital status, educational level, current work, family income, current smoking, current drinking, frequency of physical activity, but excluding itself), and chronic diseases.

${ }^{a}$ calculated only among women.

may use these factors to evaluate their overall health $[23,24]$.

Notably, most subjects rated their health positively, for only $5.72 \%$ subjects reported bad or very bad health, whereas nearly $60 \%$ rated their health as very good or good. A survey conducted in Sweden among subjects aged $18-79$ years showed that $7 \%$ of the men and $9 \%$ of the women had poor SRH [25]; thus, the prevalence rate of poor SRH in our population sample, with a similar age range as theirs, was slightly lower. An obvious higher mean age was observed as the subjects rated poorer health. This means that the subjective health status of the population significantly decreases with advancing age. Similar results were found in previous studies, which showed that age was a risk factor for poor SRH [25-29].

The prevalence of all the diseases included in our study, which was an important indicator of objective health, contributed to decreased SRH. This means that $\mathrm{SRH}$ has the ability to distinguish patients from relatively healthy people. It is noteworthy that larger ORs were found for cardio-cerebral vascular diseases, visual impairment, and mental illnesses when comparing the unhealthy group with the healthy group. An earlier study reported that with China's rapid economic development, diseases of the heart and the cerebrovascular system have become two leading causes of deaths in this country, ranking second and third among men, and first and second among women [30]. It is understandable that patients with cardio-cerebral vascular diseases are more likely to worry about their future, and that the diseases cause great cost and burden to themselves and their families; thus, people who suffer from these diseases rated poorer health. Visual impairment is associated with a decreased ability to perform activities of daily living and poor quality of life, particularly in the sense of depression and reduced social interaction [31], and patients with mental illnesses had more impairment in quality of life than those with common medical disorders [32]. These could explain why patients with visual impairment or mental illnesses rated poorer health. A previous study conducted in Sweden showed that many chronic diseases, such as neurological disease, rheumatoid arthritis, and cancer, are strongly associated with poor SRH [29]. This conclusion has been further strengthened with the evidence from our study.

Studies examining the association of SRH with laboratory parameters were still limited. In order to further elucidate this relationship in our study, we examined the laboratory parameters in the subjects who had experienced blood sampling and listed the laboratory parameters with statistical significances. We found that better SRH was associated with increased RBC and HGB, and decreased AST, TC, TG, LDL-C, and FPG. Furthermore, subjects with abnormal laboratory parameters reported poorer health. Laboratory parameters can objectively reflect health status and are of fundamental importance for the diagnosis, prognosis and treatment of various diseases [33]. The consistency of SRH and objective health status assessed by laboratory parameters is further evidence that SRH is a good indicator of health status.

In addition, the relationship between SRH and some health-related factors, which were regarded as risk factors for health, were examined. Obesity is surprisingly unrelated to poorer $\mathrm{SRH}$, and this finding is inconsistent with many previous studies $[24,25,34,35]$. On further consideration, this is also explicable. In Chinese culture, 
being fat is not a signal of unhealthiness but a symbol of acquiring good fortune, because only the more wealthy people can afford to eat more and can thus put on more weight [36]. This is quite different in Western countries. Underweight and weight loss are two risk factors observed in this study. Underweight or weight loss was linked to eating disorders such as anorexia nervosa, or consumptive diseases such as malignant tumors. The findings also support marriage as a protective factor for health [37]: subjects who were divorced or widowed rated poorer health. Subjects with higher income tended to be more optimistic about their health, because they have been observed to practice more health promoting behaviors such as good dietary intake practices and physical activity [38]. Shibuya et al. also found that low income was associated with poor SRH in a Japanese sample [7]. Lim et al. found that marital status, education, household income, current smoking, and exercise were associated with SRH in a Singaporean sample [39]. Life stress and work strain as risk factors for poor SRH have been examined less frequently in population studies. One study has demonstrated that family stress is a risk factor for unfavorable health-related outcomes [40], and another has revealed that work stress is associated with poor SRH [41]. These results support the conclusion of this study.

Our results need to be interpreted within the context of the study limitations. First, the cross-sectional nature of the study did not allow us to investigate the temporal mechanisms between SRH on the one hand and diseases or abnormalities in laboratory parameters or risk factors on the other. Second, we relied on a self-administrated questionnaire for measuring the clinical and healthrelated factors that were used to validate SRH. Except for laboratory parameters, all data relied on self-report. Like any other questionnaire study, the subjects' answers may be affected by various kinds of bias such as social desirability. Finally, the study was a part of a larger study; therefore, the research questions can only be pursued within the boundaries of the original study. Some indicators were not integrated in our study due to the original focus of the study. Nevertheless, information on the majority of, but not all, possible confounders was available for analysis. There were also other factors associated with SRH such as depression, psychological wellbeing, health service utilization, medication usage, cognitive capacity, and social networks, but data on these factors were not collected in our study. However, with the information collected, we were able to explain the relationship between SRH and the objective health status.

The strengths of this study are as follows: (1) it includes a random sample of population from five cities of China with a broad range of ages in accord with the distribution of local population, which is a better representation of the total population. In contrast the majority of previous studies focusing on SRH mainly examined older population samples $[5,13-15,17,18,42,43]$ or subjects with certain specific diseases [23,44-46]. (2) The present study investigates the association between $\mathrm{SRH}$ and objective health status from multiple dimensions, using a wide range of variables, including the prevalence of diseases, abnormalities in laboratory parameters, and health-related factors.

\section{Conclusion}

This study provides evidence of the association between $\mathrm{SRH}$ and objective health status exemplified by the prevalence of diseases, abnormalities in laboratory parameters, and health-related factors. The results lead to a conclusion that SRH can reflect the objective health status and serve as a global measure of health status in the general population. This is very important since there is hardly any individual indicator that can comprehensively evaluate a person's health status. Most of the factors influencing the SRH can be changed so as to improve health, for example, by actively treating diseases, engaging in more physical activity in daily life, improving mental well-being, and promoting adoption of healthy behaviors. It is therefore imperative for the public health sector to implement health promotion and treatment programs to target these specific goals in the community. Additionally, SRH could be used as a populationscreening tool in the Chinese health care system, which could help public health officials identify those who are most in need of their services. Further studies to qualitatively and quantitatively explore these and other related variables might further advance our understanding of $\mathrm{SRH}$ and provide insights into the influencing factors of SRH.

\section{Abbreviations}

SRH: Self-rated health; ORs: Odds ratios; WHO: World Health Organization; Euro-REVES: European Network for the Calculation of Health Expectancies; RBC: Red blood cell; HGB: Hemoglobin; AST: Aspartate aminotransferase; TC: Total cholesterol; TG: Triglyceride; LDL-C: Low-density lipoprotein cholesterol; FPG: Fasting plasma glucose; BMI: Body Mass Index; SAS: Statistical Analysis System; SD: Standard deviation; Cls: Confidence intervals.

\section{Competing interests}

SQW, RW, YFZ, XQM, MJW, and XYY have no conflict of interests. JH has served as the director of the Department of Health Statistics, Second Military Medical University.

\section{Authors' contributions}

$\mathrm{JH}$ conceived of the study and supervised all aspects of its implementation. SQW and RW assisted with the survey, completed the statistical analyses and led the writing of different versions of the manuscript. YFZ, MJW and XYY assisted with the study, and XQM assisted with the survey and data analyses. All authors contributed to conceptualize ideas, interpret findings, and review the drafts of the manuscript, and they approved the final manuscript. 


\section{Acknowledgements}

We are grateful to Qian He and Feifei Yu for their great help and assistance with the different versions of the manuscript. We also appreciate Prof. Jian Lu for his assistance in the survey.

\section{Funding}

This work was supported by the key discipline construction of evidencebased public health in Shanghai [12GWZX0602].

Received: 24 September 2012 Accepted: 1 April 2013

Published: 9 April 2013

\section{References}

1. Benjamins MR, Hummer RA, Eberstein IW, Nam CB: Self-reported health and adult mortality risk: an analysis of cause-specific mortality. Soc Sci Med 2004, 59:1297-1306

2. Idler EL, Angel RJ: Self-rated health and mortality in the NHANES-I Epidemiologic Follow-up Study. Am J Public Health 1990, 80:446-452.

3. Appels A, Bosma H, Grabauskas V, Gostautas A, Sturmans F: Self-rated health and mortality in a Lithuanian and a Dutch population. Soc Sci Med 1996, 42:681-689.

4. Goldberg P, Gueguen A, Schmaus A, Nakache JP, Goldberg M: Longitudinal study of associations between perceived health status and self reported diseases in the French Gazel cohort. J Epidemiol Community Health 2001, 55:233-238.

5. Damian J, Ruigomez A, Pastor V, Martin-Moreno JM: Determinants of self assessed health among Spanish older people living at home. J Epidemiol Community Health 1999, 53:412-416.

6. Kaplan GA, Goldberg DE, Everson SA, Cohen RD, Salonen R, Tuomilehto J, Salonen J: Perceived health status and morbidity and mortality: evidence from the Kuopio ischaemic heart disease risk factor study. Int J Epidemiol 1996, 25:259-265.

7. Shibuya K, Hashimoto H, Yano E: Individual income, income distribution, and self rated health in Japan: cross sectional analysis of nationally representative sample. BMJ 2002, 324:16-19.

8. Lindström M: Marital status, social capital, material conditions and selfrated health: a population-based study. Health Policy 2009, 93:172-179.

9. Mansyur C, Amick BC, Harrist RB, Franzini L: Social capital, income inequality, and self-rated health in 45 countries. Soc Sci Med 2008, 66:43-56.

10. Mulsant BH, Ganguli M, Seaberg EC: The relationship between self-rated health and depressive symptoms in an epidemiological sample of community-dwelling older adults. J Am Geriatr Soc 1997, 45:954-958.

11. Dasbach EJ, Klein R, Klein BE, Moss SE: Self-rated health and mortality in people with diabetes. Am J Public Health 1994, 84:1775-1779.

12. Janszky I, Lekander M, Blom M, Georgiades A, Ahnve S: Self-rated health and vital exhaustion, but not depression, is related to inflammation in women with coronary heart disease. Brain Behav Immun 2005, 19:555-563.

13. Kaplan GA, Barell V, Lusky A: Subjective state of health and survival in elderly adults. J Gerontol 1988, 43:S114-S120.

14. Maddox G: Some correlates of differences in self-assessment of health status among the elderly. J Gerontol 1962, 17:180-185.

15. Ferraro K: Self-ratings of health among the old and old-old. J Health Soc Behav 1980, 21:377-383.

16. Cockerham W, Sharp K, Wilcox J: Aging and perceived health status. J Gerontol 1983, 38:349-355.

17. Mitrushina MN, Satz P: Correlates of self-rated health in the elderly. Aging 1991, 3:73-77.

18. Fillenbaum GG: Social context and self-assessments of health among the elderly. J Health Soc Behav 1979, 20:45-51

19. Yan XY, Wang R, Zhao YF, Ma XQ, Fang JQ, Yan H, Kang XP, Yin P, Hao YT, Dent J, Sung J, Zou DW, Johansson S, Halling K, Liu WB, He J: Systematic investigation of gastrointestinal diseases in China (SILC): validation of survey methodology. BMC Gastroenterol 2009, 9:86.

20. World Health Organization SN: Health interview surveys: Towards international harmonization of methods and instruments. Copenhagen: WHO Office for Europe; 1996.

21. Robine JM, Jagger C, Euro-REVES Grp: Creating a coherent set of indicators to monitor health across Europe- the euro-REVES 2 project. Eur J Public Health 2003, 13:6-14.
22. WHO: Appropriate body-mass index for Asian populations and its implications for policy and intervention strategies. Lancet 2004, 363:157-163.

23. Bosworth HB, Siegler IC, Brummett BH, Barefoot JC, Williams RB, Vitaliano PP, Clapp-Channing N, Lytle BL, Mark DB: The relationship between self-rated health and health status among coronary arterypatients. J Aging Health 1999, 11:565-584.

24. Manderbacka K, Lundberg O, Martikainen P: Do risk factors and health behaviors contribute to self-rating of health? Soc Sci Med 1999, 48:1713-1720.

25. Molarius A, Berglund K, Eriksson C, Lambe M, Nordström E, Eriksson HG, Feldman I: Socioeconomic conditions, lifestyle factors, and self-rated health among men and women in Sweden. Eur J Public Health 2007, 17:125-133.

26. Jylhä M, Guralnik JM, Balfour J, Fried LP: Walking difficulty, walking speed, and age as predictors of self-rated health: the women's health and aging study. J Gerontol A Biol Sci Med Sci 2001, 56:M609-M617.

27. Murata C, Kondo T, Tamakoshi K, Yatsuya H, Toyoshima H: Determinants of self-rated health: could health status explain the association between self-rated health and mortality? Arch Gerontol Geriatr 2006 43:369-380.

28. Shadbolt B: Some correlates of self-rated health for Australian women. Am J Public Health 1997, 87:951-956.

29. Molarius A, Janson S: Self-rated health, chronic diseases, and symptoms among middle-aged and elderly men and women. J Clin Epidemiol 2002, 55:364-370.

30. He J, Gu D, Wu X, Reynolds K, Duan X, Yao C, Wang J, Chen CS, Chen J, Wildman RP, Klag MJ, Whelton PK: Major causes of death among men and women in China. N Engl J Med 2005, 353:1124-1134

31. Carabellese C, Appollonio I, Rozzini R, Bianchetti A, Frisoni GB, Frattola L, Trabucchi M: Sensory impairment and quality of life in a community elderly population. J Am Geriatr Soc 1993, 41:401-407.

32. Spitzer RL, Kroenke K, Linzer M, Hahn SR, Williams JB, deGruy FV 3rd, Brody $D$, Davies M: Health-related quality of life in primary care patients with mental disorders. Results from the PRIME-MD 1000 Study. JAMA 1995, 274:1511-1517.

33. Lio D, Malaguarnera M, Maugeri D, Ferlito L, Bennati E, Scola L, Motta M, Caruso C: Laboratory parameters in centenarians of Italian ancestry. Exp Gerontol 2008, 43:119-122.

34. Okosun IS, Choi S, Matamoros T, Dever GE: Obesity is associated with reduced self-rated general health status: evidence from a representative sample of white, black, and Hispanic Americans. Prev Med 2001, 32:429-436.

35. Svedberg P, Bardage C, Sandin S, Pedersen NL: A prospective study of health, life-style and psychosocial predictors of self-rated health. Eur Epidemiol 2006, 21:767-776.

36. Li ZB, Ho SY, Chan WM, Ho KS, Li MP, Leung GM, Lam TH: Obesity and depressive symptoms in Chinese elderly. Int I Geriatr Psychiatry 2004 19:68-74.

37. Markides KS, Lee DJ: Predictors of well-being and functioning in older Mexican Americans and Anglos: an eight-year follow-up. J Gerontol 1990, 45:S69-S73.

38. Popkin BM, Siega-Riz AM, Haines PS: A comparison of dietary trends among racial and socioeconomic groups in the United States. N Engl J Med 1996, 335:716-720.

39. Lim WY, Ma S, Heng D, Bhalla V, Chew SK: Gender, ethnicity, health behaviour \& self-rated health in Singapore. BMC Public Health 2007, 7:184.

40. Parkerson GR Jr, Broadhead WE, Tse CK: Perceived family stress as a predictor of health-related outcomes. Arch Fam Med 1995, 4:253-260.

41. Weyers S, Peter R, Boggild H, Jeppesen HJ, Siegrist J: Psychosocial work stress is associated with poor self-rated health in Danish nurses: a test of the effort-reward imbalance model. Scand J Caring Sci 2006 20:26-34.

42. Nybo H, Gaist D, Jeune B, McGue M, Vaupel JW, Christensen K: Functional status and self-rated health in 2262 nonagenarians: the Danish 1905 Cohort Survey. J Am Geriatr Soc 2001, 49:601-609.

43. Kivinen $\mathrm{P}$, Sulkava $R$, Halonen $\mathrm{P}$, Nissinen A: Self-reported and performance-based functional status and associated factors among elderly men: the Finnish cohorts of the Seven Countries Study. J Clin Epidemiol 1998, 51:1243-1252. 
44. Cott CA, Gignac MA, Badley EM: Determinants of self rated health for Canadians with chronic disease and disability. I Epidemiol Community Health 1999, 53:731-736.

45. Mäntyselkä PT, Turunen JH, Ahonen RS, Kumpusalo EA: Chronic pain and poor self-rated health. JAMA 2003, 290:2435-2442.

46. Ruo B, Bertenthal D, Sen S, Bittner V, Ireland CC, Hlatky MA: Self-rated health among women with coronary disease: depression is as important as recent cardiovascular events. Am Heart J 2006, 152:921. e1-e7.

doi:10.1186/1471-2458-13-320

Cite this article as: Wu et al:: The relationship between self-rated health and objective health status: a population-based study. BMC Public Health 2013 13:320.

\section{Submit your next manuscript to BioMed Central and take full advantage of:}

- Convenient online submission

- Thorough peer review

- No space constraints or color figure charges

- Immediate publication on acceptance

- Inclusion in PubMed, CAS, Scopus and Google Scholar

- Research which is freely available for redistribution 